\title{
Temporal trends in mode, site and stage of presentation with the introduction of colorectal cancer screening: a decade of experience from the West of Scotland
}

\author{
D Mansouri ${ }^{*}{ }^{1}$, D C McMillan ${ }^{1}$, C Crearie ${ }^{2}$, D S Morrison ${ }^{3}$, E M Crighton ${ }^{4}$ and P G Horgan ${ }^{1}$ \\ ${ }^{1}$ Academic Unit of Colorectal Surgery, College of Medical, Veterinary and Life Sciences, University of Glasgow, Glasgow Royal \\ Infirmary, Room 2.57, New Lister Building, Glasgow Royal Infirmary, 10-16 Alexandra Parade, Glasgow G31 2ER, UK; \\ ${ }^{2}$ West of Scotland Cancer Network, Glasgow Royal Infirmary, Glasgow, UK; ${ }^{3}$ West of Scotland Cancer Surveillance Unit, Lillybank \\ Gardens, Glasgow, UK and ${ }^{4}$ Department of Public Health Screening Unit, NHS Greater Glasgow \& Clyde, West House, Gartnavel \\ Royal Hospital, Glasgow, UK
}

Background: Population colorectal cancer screening programmes have been introduced to reduce cancer-specific mortality through the detection of early-stage disease. The present study aimed to examine the impact of screening introduction in the West of Scotland.

Methods: Data on all patients with a diagnosis of colorectal cancer between January 2003 and December 2012 were extracted from a prospectively maintained regional audit database. Changes in mode, site and stage of presentation before, during and after screening introduction were examined.

Results: In a population of 2.4 million, over a 10-year period, 14487 incident cases of colorectal cancer were noted. Of these, 7827 (54\%) were males and 7727 (53\%) were socioeconomically deprived. In the postscreening era, 18\% were diagnosed via the screening programme. There was a reduction in both emergency presentation ( $20 \%$ prescreening vs $13 \%$ postscreening, $P \leqslant 0.001)$ and the proportion of rectal cancers (34\% prescreening vs $31 \%$ pos-screening, $P \leqslant 0.001)$ over the timeframe. Within nonmetastatic disease, an increase in the proportion of stage I tumours at diagnosis was noted (17\% prescreening vs $28 \%$ postscreening, $P \leqslant 0.001)$.

Conclusions: Within non-metastatic disease, a shift towards earlier stage at diagnosis has accompanied the introduction of a national screening programme. Such a change should lead to improved outcomes in patients with colorectal cancer.

Several large randomised control trials examining guaiac-based faecal occult blood test (gFOBt) colorectal cancer screening programmes have shown a reduction in cancer-specific mortality through the detection of early-stage disease (Mandel et al, 1993; Kronborg et al, 1996; Scholefield et al, 2002). Therefore, national bowel screening programmes have been introduced across the United Kingdom over the past 10 years. However, it is important to consider screening within the context of the whole population that is being served by the screening programme. For example, the current Scottish Bowel Screening Programme (SBoSP) is targeted only at those aged between 50 and 74 years, with few over the age of 74 years opting for further testing. In addition, there is limited uptake, sensitivity and specificity of the testing algorithms in use. Therefore, clearly, not all tumours will be screen detected, and it is unclear what the overall impact on the population will be. 
Indeed, a previous single centre study from Scotland has suggested that screen-detected tumours may account for just $17 \%$ of all tumours diagnosed within a population invited to screening (Roxburgh et al, 2013). Additionally, it has been noted that despite the programme detecting an increased number of early-stage tumours, it may not lead to an overall stage shift to earlier disease across the population (Roxburgh et al, 2013).

The aim of the present study was to examine the impact that screening has had on the mode, site and stage of presentation of colorectal cancer in the West of Scotland over the past decade. The aim was to achieve this by using population statistics from the West of Scotland Managed Clinical Network (MCN) to compare cohorts before, during and after the introduction of the SBoSP.

\section{PATIENTS AND METHODS}

The MCN covers four Health Boards (Ayrshire and Arran, Forth Valley, Greater Glasgow and Clyde and Lanarkshire) comprising 16 different hospitals and covering a population of over 2.4 million, just under half of the population of Scotland (Table 1). It was created in 2000 with the aim of improving outcomes in colorectal cancer. All patients discussed at a local hospital multidisciplinary team (MDT) with a diagnosis of colorectal cancer are included, with the clinicopathological data prospectively recorded. Details including age, sex, socioeconomic deprivation status, mode of presentation and tumour site and stage are routinely stored. For the present study, data were extracted for a period from 1 st January 2003 to 31st December 2012.

The mode of presentation was defined as emergency if the patient underwent management involving a hospital admission that was unplanned. This included, but was not limited to, significant rectal bleeding, colonic obstruction and perforation. Other routes were defined as elective including screen detected, which was introduced as a data point from 2007 onwards.

Tumour site was classified according to anatomical site as per the International Classification of Disease version 10 (ICD-10). Lesions up to, but not including, the splenic flexure were classified

Table 1. Population of NHS Health Boards across Scotland, date of screening introduction and uptake of test

\begin{tabular}{|c|c|c|c|}
\hline $\begin{array}{l}\text { NHS Health } \\
\text { Board }\end{array}$ & $\begin{array}{l}\text { Population } \\
\text { (est. 2009) }\end{array}$ & $\begin{array}{l}\text { Screening } \\
\text { introduction }\end{array}$ & $\begin{array}{c}\text { Screening } \\
\text { uptake (\%) }\end{array}$ \\
\hline Grampian & 559210 & June 2007 & 61 \\
\hline Fife & 361410 & June 2007 & 56 \\
\hline Tayside & 404390 & June 2007 & 59 \\
\hline $\begin{array}{l}\text { Ayshire and } \\
\text { Arran }\end{array}$ & 372380 & $\begin{array}{l}\text { September } \\
2007\end{array}$ & 55 \\
\hline Orkney & 20940 & October 2007 & 63 \\
\hline Forth Valley & 294140 & December 2007 & 55 \\
\hline Lothian & 816640 & May 2008 & 54 \\
\hline Western Isles & 27420 & July 2008 & 57 \\
\hline $\begin{array}{l}\text { Dumfries and } \\
\text { Galloway }\end{array}$ & 151160 & December 2008 & 58 \\
\hline $\begin{array}{l}\text { Greater Glasgow } \\
\text { and Clyde }\end{array}$ & 1199830 & April 2009 & 53 \\
\hline Lanarkshire & 569800 & August 2009 & 48 \\
\hline Shetland & 22790 & October 2009 & 64 \\
\hline Borders & 113380 & November 2009 & 60 \\
\hline Highland & 318200 & December 2009 & 61 \\
\hline \multicolumn{4}{|c|}{$\begin{array}{l}\text { Abbreviation: NHS = National Health Service. } \\
\text { a Derived from invitations between 1st November } 2010 \text { and } 31 \text { st October } 2012 \text { (Information } \\
\text { Services Division Scotland (ISD), 2013). }\end{array}$} \\
\hline
\end{tabular}

as right sided (C18.0-C18.4), those from splenic flexure up to, but not including, the retosigmoid junction were defined as left sided (CC18.5-C18.7) and tumours of the rectosigmoid junction and rectum were classed as rectal (C19 and C20). Tumour stage was defined according to the standard TNM (version 5) classification (Sobin and Fleming, 1997) based on histological resection of specimens and, in those who did not under go resection, on preoperative imaging modalities. Polyp cancers, which underwent endoscopic excision only, were classified as stage I disease. Intent of procedure was collated at the time of resection as either curative or palliative by the surgical team responsible for each individual patient.

Socioeconomic deprivation status was calculated from the Scottish Index of Multiple Deprivation, which is an index of relative deprivation (Scottish Government, 2009). Quintiles of deprivation were used to assign individuals to a relative deprivation category based on their postcode at their time of diagnosis, with the first quintile representing the most deprived and the fifth quintile, the least deprived. The most current version of SIMD was used at the time of data collection (i.e., SIMD 2004 for patients in 2003 to 2005, SIMD 2006 for patients in 2006, 2007 and 2008 .and so on).

The SBoSP is a biennial gFOBt/faecal immunochemical test (FIT)-based screening programme for all individuals aged 50-74 years. Details regarding the current screening algorithm have been published previously (Fraser et al, 2012). Briefly, all individuals aged 50-74 years are sent a preinvitation letter and then a gFOBt, and later referred for colonoscopy if this is returned and is strongly positive ( $\geqslant 5$ of 6 windows positive). In the case of a weakly positive gFOBt (1-4 of 6 windows positive), spoiled or untestable kit, a confirmatory FIT is sent. Individuals then proceed to colonoscopy, following preassessment by a bowel screening preassessment nurse. Screening was introduced across the four Health Boards at staged intervals (Table 1); therefore, the data were separated into five distinct time frames: 2003-2004 early prescreening (EPrS), 2005-2006 late prescreening, 2007-2008 early introduction of screening, where the minority of the population were invited, 2009-2010 late introduction of screening, where the majority of the population were invited and 2011 to 2012 postintroduction of screening (PoS), where screening had been introduced across all four boards. This allowed for assessment not only of the impact of screening but also of the temporal changes in disease presentation and management across the area over the decade.

Permission for the study was granted by the Caldicott guardian for the data and all data were stored and analysed in an anonymised manner

Statistical analyses. The $\chi^{2}$ test for linear trend was used to test associations between variables and calendar time. A $P$-value $\leqslant 0.05$ was considered statistically significant. Statistical analysis was performed using the SPSS software (SPSS Inc., Chicago, IL, USA)

\section{RESULTS}

From 1st January 2003 to 31st December 2012, inclusive, there were 14487 incident cases of colorectal cancer. There were 7827 (54\%) males, 8142 (56\%) patients were between 50 and 74 years old and 7727 (53\%) patients were in the two most deprived quintiles of deprivation. Overall, 2163 (15\%) patients presented to surgery as an emergency (Table 2).

On examining patient demographics over the decade of analysis, there were no changes seen in the age and sex of patients at diagnosis; however, there was a weak trend for those in PoS to be more deprived in later years $(P=0.057)$. There was a significant reduction in the proportion of patients presenting to surgery as an 
Table 2. Temporal trends in colorectal cancer presentation with the introduction of screening

\begin{tabular}{|c|c|c|c|c|c|c|c|c|c|c|c|c|c|}
\hline & \multicolumn{2}{|c|}{ All patients } & \multicolumn{4}{|c|}{ Pre-screening } & \multicolumn{4}{|c|}{ Screening introduction } & \multicolumn{3}{|c|}{ Postscreening } \\
\hline & & & \multicolumn{2}{|l|}{ Early } & \multicolumn{2}{|l|}{ Late } & \multicolumn{2}{|l|}{ Early } & \multicolumn{2}{|l|}{ Late } & \multirow{2}{*}{\multicolumn{2}{|c|}{ 2011-2012 }} & \multirow[b]{3}{*}{$P$-value } \\
\hline & & & \multicolumn{2}{|c|}{ 2003-2004 } & \multicolumn{2}{|c|}{ 2005-2006 } & \multicolumn{2}{|c|}{ 2007-2008 } & \multicolumn{2}{|c|}{ 2009-2010 } & & & \\
\hline & $n(14487)$ & $\%$ & $n(2380)$ & $\%$ & $n(2384)$ & $\%$ & $n(3098)$ & $\%$ & $n(3282)$ & $\%$ & $n(3343)$ & $\%$ & \\
\hline \multicolumn{14}{|l|}{ Age (years) } \\
\hline$\leqslant 50$ & 751 & 5 & 129 & 5 & 129 & 5 & 172 & 6 & 139 & 4 & 182 & 5 & \\
\hline $50-74$ & 8142 & 56 & 1250 & 53 & 1368 & 57 & 1702 & 55 & 1897 & 58 & 1925 & 58 & \\
\hline$\geqslant 75$ & 5299 & 37 & 851 & 35 & 793 & 33 & 1202 & 39 & 1224 & 37 & 1229 & 37 & 0.584 \\
\hline Unknown & 295 & 2 & 150 & 6 & 94 & 4 & 22 & 1 & 23 & 1 & 6 & 0 & \\
\hline \multicolumn{14}{|l|}{ Sex } \\
\hline Female & 6364 & 44 & 1017 & 42 & 1054 & 44 & 1384 & 45 & 1416 & 43 & 1493 & 45 & \\
\hline Male & 7827 & 54 & 1213 & 51 & 1236 & 52 & 1692 & 55 & 1843 & 56 & 1843 & 55 & 0.169 \\
\hline Unknown & 296 & 2 & 150 & 6 & 94 & 4 & 22 & 1 & 23 & 1 & 7 & 0 & \\
\hline \multicolumn{14}{|l|}{ Deprivation category } \\
\hline 1 (most deprived) & 4329 & 30 & 667 & 28 & 706 & 30 & 935 & 30 & 978 & 30 & 1043 & 31 & \\
\hline 2 & 3398 & 23 & 545 & 23 & 555 & 23 & 732 & 24 & 776 & 24 & 790 & 24 & \\
\hline 3 & 2370 & 16 & 364 & 15 & 380 & 16 & 529 & 17 & 557 & 17 & 540 & 16 & \\
\hline 4 & 1921 & 13 & 307 & 13 & 300 & 13 & 406 & 13 & 433 & 13 & 475 & 14 & \\
\hline 5 (least deprived) & 2072 & 14 & 247 & 16 & 349 & 15 & 474 & 15 & 514 & 16 & 488 & 15 & 0.057 \\
\hline Unknown & 297 & 2 & 150 & 6 & 94 & 4 & 22 & 1 & 24 & 1 & 7 & 0 & \\
\hline \multicolumn{14}{|l|}{ Presentation to surgery } \\
\hline Emergency & 2163 & 15 & 480 & 20 & 431 & 18 & 414 & 13 & 420 & 13 & 418 & 13 & \\
\hline Elective & & & & & & & & & & & & & \\
\hline Symptomatic & 8948 & 62 & 1849 & 78 & 1868 & 78 & 1910 & 62 & 1729 & 53 & 1592 & 47 & \\
\hline Screen detected ${ }^{a}$ & 1200 & 8 & - & - & - & - & 107 & 3 & 486 & 15 & 607 & 18 & $\leqslant 0.001^{b}$ \\
\hline Did not undergo procedure & 2056 & 14 & 30 & 1 & 56 & 2 & 624 & 20 & 642 & 20 & 704 & 21 & \\
\hline Unknown & 115 & 1 & 21 & 5 & 29 & 3 & 43 & 1 & 5 & 0 & 22 & 1 & \\
\hline \multicolumn{14}{|l|}{ Site of tumour } \\
\hline Right colon & 4857 & 34 & 753 & 32 & 811 & 34 & 1048 & 34 & 1099 & 34 & 1146 & 34 & \\
\hline Left colon & 4827 & 33 & 790 & 33 & 736 & 31 & 997 & 32 & 1165 & 35 & 1139 & 34 & \\
\hline Rectum & 4647 & 32 & 825 & 34 & 818 & 34 & 996 & 32 & 983 & 30 & 1025 & 31 & 0.001 \\
\hline Multiple/unknown & 156 & 1 & 12 & 1 & 19 & 1 & 57 & 2 & 35 & 1 & 33 & 1 & \\
\hline \multicolumn{14}{|l|}{ Management Intent } \\
\hline Curative intent & 9980 & 68 & 1797 & 76 & 1744 & 73 & 1972 & 64 & 2238 & 68 & 2229 & 67 & \\
\hline Palliative procedure & 1877 & 13 & 440 & 18 & 389 & 16 & 337 & 11 & 334 & 10 & 377 & 11 & $\leqslant 0.001^{c}$ \\
\hline Did not undergo procedure & 2056 & 14 & 30 & 1 & 56 & 2 & 624 & 20 & 642 & 20 & 704 & 21 & \\
\hline Unknown/other & 574 & 4 & 113 & 5 & 195 & 8 & 165 & 5 & 68 & 2 & 33 & 1 & \\
\hline
\end{tabular}

emergency over the timeframe from 20\% EPrS to $13 \%$ PoS $(P \leqslant 0.001)$ (Table 2$)$.

On examining tumour characteristics, there was a reduction in the proportion of rectal cancers diagnosed over the timeframe from $34 \% \mathrm{EPrS}$ to $31 \% \operatorname{PoS}(P=0.001)$. Comparing procedure intent, excluding those who did not undergo a procedure, more patients underwent a procedure with a curative intent in later years $(76 \%$ EPrS vs 84\% PoS, $P \leqslant 0.001$ ) (Table 2). Overall, 3379 (23\%) patients had incomplete TNM staging information and 708 (5\%) patients had evidence of distant metastatic disease. These were subsequently excluded from analysis and stage I-III disease was examined independently. Over the timeframe, there was a shift among those without distant metastases towards a higher proportion of stage I cancers in later years (17\% EPrS vs $28 \% \operatorname{PoS}, P \leqslant 0.001)$ (Table 3).

Patients with colorectal cancer diagnosed in the PoS timeframe were further examined to compare screen-detected and nonscreen-detected disease (Table 4). Patients with screen-detected disease were more likely to be younger $(P \leqslant 0.001)$, male $(P \leqslant 0.001)$, less deprived $(P=0.002)$ and present electively $(P \leqslant 0.001)$. In addition screen-detected tumours were more likely to be distal $(P \leqslant 0.001)$, of an earlier stage $(P \leqslant 0.001)$ and managed with a curative intent $(P \leqslant 0.001)$.

\section{DISCUSSION}

The results of the present study provide an overview of the changes in mode, site and stage of colorectal cancer presentation in a single geographical area over the past decade, accompanying the introduction of a national screening programme. The results show a reduction in emergency presentation, a reduction in the proportion of rectal cancers and a shift among those without distant metastases to earlier stage at diagnosis. Furthermore, an overall increase in the proportion of patients managed with a curative intent has been identified.

Examining the impact of screening on overall TNM stage at presentation using population-based data sets can be problematic. This is because of high number of patients with incomplete staging information and limited information on those with metastatic disease. For example, in a recent population study examining tumours diagnosed within and without the English Bowel Cancer Screening Programme, 25\% of cases were unstaged (Morris et al, 2012), similar to the present study. In addition, patients who do not have complete staging information are more likely to die closer to their time of diagnosis, implying the presence of more advanced disease (Downing et al, 2013). 
Table 3. Temporal trends in TNM stage of colorectal cancer at presentation with the introduction of screening (non-metastatic disease only)

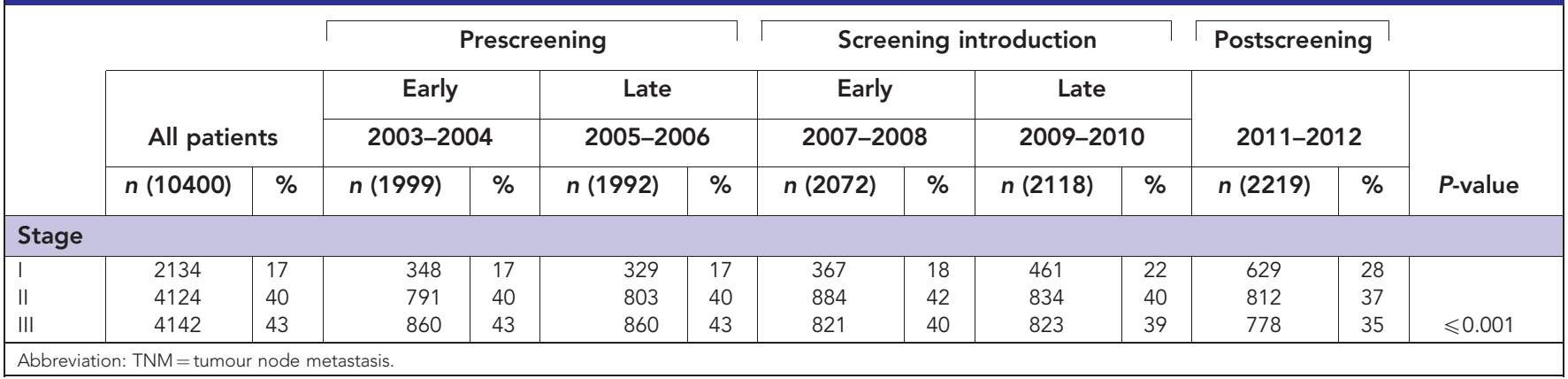

The MCN has been created to improve outcome in colorectal cancer through delivery of high-quality care with a focus on surgical outcomes. Data are collated following local MDT discussion; therefore, information on patients with metastatic disease who are managed palliatively is poorly captured. It is recognised that this limitation of the data set is particularly true in the early cohorts. For example, only $1 \%$ of patients in the EPrS timeframe did not undergo a procedure compared with $20 \%$ of patients in PoS timeframe. Furthermore, examining stage IV disease across the timeframe actually showed an increase from 3\% (EPrS) to $9 \%(\mathrm{PoS})$ with a concurrent rise in unstaged disease from $13 \%$ (EPrS) to $25 \%$ (PoS) (data not presented). However, this clearly identifies a failure in capture of metastatic or incompletely staged patients of the MCN data set.

Therefore, to maintain data quality when examining stage, the present study chose to focus only on those without distant metastases. When this was considered separately, a clear trend towards larger proportions of node-negative and stage I disease following screening introduction was seen. It has been reported that tumours detected through the screening pathway are of an earlier stage compared with non-screen detected and the present study supports this finding (Morris et al, 2012; Roxburgh et al, 2013). In addition, despite only accounting for $18 \%$ of all tumours diagnosed, an overall impact on the population has been noted. Such a change may well be associated not only with the test itself but also with an overall improvement in the knowledge and attitudes of the population with the widespread publication of screening information. However, a degree of caution should be excercised in interpreting this stage shift among those without distant metastases, as it has been shown that the proportion of stage I disease may well reduce with successive screening rounds (Steele et al, 2009). Hence, further work examining the impact on stage at a population level as subsequent rounds of screening occur is required for clarification.

Emergency presentation has long been associated with both poorer short-term (Anderson et al, 1992; McArdle and Hole, 2004) and long-term outcomes (McMillan et al, 2010; Gunnarsson et al, 2011). This disparity has been shown to exist even when nodenegative disease is examined independently (Oliphant et al, 2014). The reason for this poorer outcome appears multifactorial incorporating elements such as tumour characteristics (Wong et al, 2008), preoperative patient morbidity (Skala et al, 2009), use of a specialist surgeon (Biondo et al, 2010) and the presence of an elevated host preoperative systemic inflammatory response (Crozier et al, 2009). There is evidence from the Nottingham gFOBt screening trial that emergency presentation is reduced in a population undergoing screening (Scholefield et al, 1998). In addition, the Coventry arm of the population pilot study reported similar findings, with emergency admissions from colorectal cancer reducing from $29 \%$ in 1999 to $16 \%$ in 2004, with a concomitant improvement in 30-day mortality, following screening introduction (Goodyear et al, 2008). Interestingly, the present study showed a reduction in the proportion of emergency presentation before the introduction of screening; however, little change occurs during its rollout and widespread adoption. It therefore questions the impact that screening itself has had on overall emergency presentation in our geographical area. This is in keeping with a recently published cohort study, which has shown that emergency admissions are reduced when comparing participants and non-participants in screening; however, they remain similar comparing cohorts invited and not invited to screening (Libby et al, 2014). Therefore, it appears that it is participation and not invitation that is the key determinant in reducing emergency admissions.

In the present study, only $18 \%$ of all patients in the PoS cohort presented through the screening programme. This is on the background of an overall uptake of screening in our geographical region of $52 \%$, with lower uptake in the most deprived cohorts (Mansouri et al, 2013). Higher rates of emergency presentation are associated with socioeconomic deprivation and elderly age (Gunnarsson et al, 2013). However, such deprived patients are less likely to choose to participate in screening (Steele et al, 2010; von Wagner et al, 2011) and patients over the age of 74 years are currently not routinely invited to screening. Moreover, it has previously been shown that those patients who are socioeconomically deprived have a worse outcome following a diagnosis of colorectal cancer (Kelsall et al, 2009; Oliphant et al, 2013). Hence, the current screening programme may underserve the very people who do worse. Efforts to improve uptake of the programme should therefore be made to target such subgroups. One of the concerns raised regarding screening is that it may widen the gap in outcomes that has been created by socioeconomic deprivation and this may be associated with its effect on the rate of emergency presentation.

Strengths and limitations. The strengths of the present study are its size and the prospectively collected core data set including data on emergency presentation. It is recognised that there are issues with utilising population-based databases such as missing data. Nevertheless, such prospective data sets provide an opportunity to examine overall trends. Furthermore, there are additional tumour and host variables that determine outcome independent of TNM stage, which would be of interest to explore; however, these were not collected prospectively over the time period. This is particularly relevant for stage II disease, where outcome can be varied (Roxburgh et al, 2014; Park et al, 2015). Further work with mature follow-up and detailed tumour and host information is required to assess the impact on outcome in particular in stage II disease. A further limitation is utilising data over a decade, where staging modalities may have altered. For example, changes in the sensitivity of CT in detecting metastatic disease or changes in the approach to the pathological processing of specimens may have led to a comparative understaging of those in the earlier cohorts (i.e., a 
Table 4. Comparison of screen- and non-screen-detected colorectal cancer in the postscreening era (2011/12)

\begin{tabular}{|l|r|r|r|r|r|r|r|r|}
\hline \multicolumn{7}{|c|}{ All patients } & $\begin{array}{r}\text { Screen } \\
\text { detected }\end{array}$ Non-screen \\
detected
\end{tabular}

more attentive approach to lymph node examination in later years). However, such bias is difficult to avoid when examining historical data. Finally, our definition of emergency presentation includes those admitted with acute bleeding. Recently, it has been reported that those patients with colorectal cancer who present with GI bleeding have a better outcome than others, and as such grouping these along with colonic perforation and obstruction is suboptimal (Alexiusdottir et al, 2013). Nevertheless, this was the definition of an emergency as coded prospectively in the data set and therefore precluded more detailed analysis.

In conclusion, examining population data from the West of Scotland over the past decade has identified that the SBoSP now accounts for $18 \%$ of all tumours encountered in clinical practice. Over the past decade, accompanying the introduction of screening, there has been a reduction in the rate of emergency presentation, a rise in the proportion of operative procedures performed with a curative intent and, in patients with no evidence of distant metastases, a shift towards an increased number of earlier stage tumours. These changes are likely to improve outcomes overall in the West of Scotland for patients presenting with colorectal cancer; however, there is a need for high-quality follow-up to establish this.

\section{REFERENCES}

Alexiusdottir KK, Snaebjornsson P, Tryggvadottir L, Jonasson L, Olasfsdottir EJ, Bjornsson ES, Moller PH, Jonasson JG (2013) Colon cancer: association of histopathological parameters and patients' survival with clinical presentation. APMIS 121: 901-907.

Anderson JH, Hole D, McArdle CS (1992) Elective versus emergency surgery for patients with colorectal cancer. Br J Surg 79: 706-709.

Biondo S, Kreisler E, Millan M, Fraccalvieri D, Golda T, Frago R, Miguel B (2010) Impact of surgical specialization on emergency colorectal surgery outcomes. Arch Surg 145: 79-86.

Crozier JE, Leitch EF, McKee RF, Anderson JH, Horgan PG, McMillan DC (2009) Relationship between emergency presentation, systemic inflammatory response, and cancer-specific survival in patients undergoing potentially curative surgery for colon cancer. Am J Surg 197: 544-549.

Downing A, Aravani A, Macleod U, Oliver S, Finan PJ, Thomas JD, Quirke P, Wilkinson JR, Morris EJ (2013) Early mortality from colorectal cancer in England: a retrospective observational study of the factors associated with death in the first year after diagnosis. $\mathrm{Br} J$ Cancer 108: 681-685.

Fraser CG, Digby J, McDonald PJ, Strachan JA, Carey FA, Steele RJ (2012) Experience with a two-tier reflex gFOBT/FIT strategy in a national bowel screening programme. J Med Screen 19: 8-13.

Goodyear SJ, Leung E, Menon A, Pedamallu S, Williams N, Wong LS (2008) The effects of population-based faecal occult blood test screening upon emergency colorectal cancer admissions in Coventry and north Warwickshire. Gut 57: 218-222.

Gunnarsson H, Ekholm A, Olsson LI (2013) Emergency presentation and socioeconomic status in colon cancer. Eur J Surg Oncol 39: 831-836.

Gunnarsson H, Holm T, Ekholm A, Olsson LI (2011) Emergency presentation of colon cancer is most frequent during summer. Colorectal Dis 13: 663-668.

Information Services Division Scotland (ISD) (2013) Scottish Bowel Screening Programme Key Performance Indicators Annual Report. Available at http://www.isdscotland.org/Health-Topics/Cancer/Bowel-Screening/ (last accessed April 2015).

Kelsall HL, Baglietto L, Muller D, Haydon AM, English DR, Giles GG (2009) The effect of socioeconomic status on survival from colorectal cancer in the Melbourne Collaborative Cohort Study. Soc Sci Med 68: 290-297.

Kronborg O, Fenger C, Olsen J, Jorgensen OD, Sondergaard O (1996) Randomised study of screening for colorectal cancer with faecaloccult-blood test. Lancet 348: 1467-1471.

Libby G, Brewster DH, Steele RJ (2014) Impact of faecal occult blood test screening on emergency admissions and short-term outcomes for colorectal cancer. Br J Surg 101: 1607-1615.

Mandel JS, Bond JH, Church TR, Snover DC, Bradley GM, Schuman LM, Ederer F (1993) Reducing mortality from colorectal cancer by screening for fecal occult blood. Minnesota Colon Cancer Control Study. $N$ Engl J Med 328: 1365-1371.

Mansouri D, McMillan DC, Grant Y, Crighton EM, Horgan PG (2013) The impact of age, sex and socioeconomic deprivation on outcomes in a colorectal cancer screening programme. PLoS One 8: e66063.

McArdle CS, Hole DJ (2004) Emergency presentation of colorectal cancer is associated with poor 5-year survival. Br J Surg 91: 605-609.

McMillan DC, McArdle CS, Morrison DS (2010) A clinical risk score to predict 3-, 5- and 10-year survival in patients undergoing surgery for Dukes B colorectal cancer. Br J Cancer 103: 970-974.

Morris EJ, Whitehouse LE, Farrell T, Nickerson C, Thomas JD, Quirke P, Rutter MD, Rees C, Finan PJ, Wilkinson JR, Patnick J (2012) A retrospective observational study examining the characteristics and outcomes of tumours diagnosed within and without of the English NHS Bowel Cancer Screening Programme. Br J Cancer 107: 757-764.

Oliphant R, Mansouri D, Nicholson GA, McMillan DC, Horgan PG, Morrison DS. West of Scotland Colorectal Cancer Managed Clinical Network (2014) Emergency presentation of node-negative colorectal cancer treated with 
curative surgery is associated with poorer short and longer-term survival. Int J Colorectal Dis 29: 591-598.

Oliphant R, Nicholson GA, Horgan PG, Molloy RG, McMillan DC, Morrison DS. West of Scotland Colorectal Cancer Managed Clinical Network (2013) Deprivation and Colorectal Cancer Surgery: longer-term survival inequalities are due to differential postoperative mortality between socioeconomic groups. Ann Surg Oncol 20: 2132-2139.

Park JH, Watt DG, Roxburgh CS, Horgan PG, McMillan DC (2015) Colorectal cancer, systemic inflammation, and outcome: staging the tumour and staging the host. Ann Surg. (E-pub ahead of print).

Roxburgh CS, McMillan DC, Richards CH, Atwan M, Anderson JH, Harvey T, Horgan PG, Foulis AK (2014) The clinical utility of the combination of $\mathrm{T}$ stage and venous invasion to predict survival in patients undergoing surgery for colorectal cancer. Ann Surg 259: 1156-1165.

Roxburgh CS, McTaggart F, Balsitis M, Diament RH (2013) The impact of the bowel screening programme on the diagnosis of colorectal cancer in Ayrshire and Arran. Colorectal Dis 15: 34-41.

Scholefield JH, Moss S, Sufi F, Mangham CM, Hardcastle JD (2002) Effect of faecal occult blood screening on mortality from colorectal cancer: results from a randomised controlled trial. Gut 50: 840-844.

Scholefield JH, Robinson MH, Mangham CM, Hardcastle JD (1998) Screening for colorectal cancer reduces emergency admissions. Eur J Surg Oncol 24: $47-50$.

Scottish Government (2009) Scottish Index of Multiple Deprivation: 2009 General Report Available at http://www.gov.scot/Topics/Statistics/SIMD/ Publications.
Skala K, Gervaz P, Buchs N, Inan I, Secic M, Mugnier-Konrad B, Morel P (2009) Risk factors for mortality-morbidity after emergency-urgent colorectal surgery. Int J Colorectal Dis 24: 311-316.

Sobin LH, Fleming ID (1997) TNM Classification of Malignant Tumors, fifth edition (1997). Union Internationale Contre le Cancer and the American Joint Committee on Cancer. Cancer 80: 1803-1804.

Steele RJ, Kostourou I, McClements P, Watling C, Libby G, Weller D, Brewster DH, Black R, Carey FA, Fraser CG (2010) Effect of gender, age and deprivation on key performance indicators in a FOBT-based colorectal screening programme. J Med Screen 17: 68-74.

Steele RJ, McClements PL, Libby G, Black R, Morton C, Birrell J, Mowat NA, Wilson JA, Kenicer M, Carey FA, Fraser CG (2009) Results from the first three rounds of the Scottish demonstration pilot of FOBT screening for colorectal cancer. Gut 58: 530-535.

von Wagner C, Baio G, Raine R, Snowball J, Morris S, Atkin W, Obichere A, Handley G, Logan RF, Rainbow S, Smith S, Halloran S, Wardle J (2011) Inequalities in participation in an organized national colorectal cancer screening programme: results from the first 2.6 million invitations in England. Int J Epidemiol 40: 712-718.

Wong SK, Jalaludin BB, Morgan MJ, Berthelsen AS, Morgan A, Gatenby AH, Fulham SB (2008) Tumor pathology and long-term survival in emergency colorectal cancer. Dis Colon Rectum 51: 223-230.

This work is published under the standard license to publish agreement. After 12 months the work will become freely available and the license terms will switch to a Creative Commons AttributionNonCommercial-Share Alike 4.0 Unported License. 